\title{
The role of medical records in the provision of public healthcare services in the Limpopo province of South Africa
}

\begin{tabular}{|c|c|}
\hline \multicolumn{2}{|c|}{$\begin{array}{l}\text { Authors: } \\
\text { Ngoako S. Marutha }^{1} \\
\text { Mpho Ngoepe }^{1}\end{array}$} \\
\hline \multicolumn{2}{|c|}{$\begin{array}{l}\text { Affiliations: } \\
{ }^{1} \text { Department of Information } \\
\text { Science, College of Human } \\
\text { Sciences, University of } \\
\text { South Africa, South Africa }\end{array}$} \\
\hline \multicolumn{2}{|c|}{$\begin{array}{l}\text { Corresponding author: } \\
\text { Mpho Ngoepe, } \\
\text { ngoepms@unisa.ac.za }\end{array}$} \\
\hline \multicolumn{2}{|c|}{$\begin{array}{l}\text { Dates: } \\
\text { Received: } 07 \text { Apr. } 2017 \\
\text { Accepted: } 05 \text { Aug. } 2017 \\
\text { Published: } 27 \text { Sept. } 2017\end{array}$} \\
\hline \multicolumn{2}{|c|}{$\begin{array}{l}\text { How to cite this article: } \\
\text { Marutha, N.S. \& Ngoepe, M., } \\
2017 \text {, 'The role of medical } \\
\text { records in the provision of } \\
\text { public healthcare services in } \\
\text { the Limpopo province of } \\
\text { South Africa', South African } \\
\text { Journal of Information } \\
\text { Management 19(1), a873. } \\
\text { https://doi.org/10.4102/ } \\
\text { sajim.v19i1.873 }\end{array}$} \\
\hline \multicolumn{2}{|c|}{$\begin{array}{l}\text { Copyright: } \\
\text { (C) 2017. The Authors. } \\
\text { Licensee: AOSIS. This } \\
\text { is licensed under the } \\
\text { Creative Commons } \\
\text { Attribution License. }\end{array}$} \\
\hline \multicolumn{2}{|l|}{ Read online: } \\
\hline 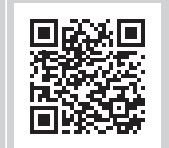 & $\begin{array}{l}\text { Scan this QR } \\
\text { code with your } \\
\text { smart phone or } \\
\text { mobile device } \\
\text { to read online. }\end{array}$ \\
\hline
\end{tabular}

Background: The importance of medical records to the provision of healthcare services cannot be overemphasised. Medical practitioners need information about previous diagnoses, treatments and prescriptions in order to note the progress made with previous treatments and how to move forward. If medical records are not managed properly, it becomes difficult to retrieve such records, which results in hospitals not being able to render healthcare services or these services being rendered incorrectly, especially for chronic patients. Despite the importance of medical records, they are not being managed properly, resulting in a lack of effective systems for opening, tracking and indexing files.

Objective: This study seeks to investigate the role of medical records in the provision of public healthcare services in the Limpopo province of South Africa.

Method: Quantitative data were collected through questionnaires distributed to staff members in the records management unit and the information management unit in 40 hospitals in Limpopo. These units were relevant as they made use of patient files daily to discharge their duties.

Results: The study revealed that missing medical records negatively affected timely and effective healthcare service delivery. This resulted in patients having to wait longer to be treated and in some instances patients being treated without medical history.

Conclusion: The study concludes by arguing that missing files contribute to the length of time patients wait to be assisted. As a result, nurses and doctors are unable to assist patients or treat them immediately. The study recommends the introduction of an electronic records management system that can capture and provide access to a full patient record, as well as tracking paper records movement, irrespective of the location.

\section{Introduction}

Many professions such as accounting, auditing, health, finance, human resources and law rely on the strength of records management to perform their duties. Records are created and managed with the intention of supporting the accurate and efficient delivery of services in many areas. For example, Katuu (2016) highlights several studies within the public sector in South Africa that demonstrate the role of records management in various areas such as: the auditing process (Ngoepe 2012; Ngoepe \& Ngulube 2016), provision of justice systems (Ngoepe \& Makhubela 2015), service delivery and human rights (Ngoepe 2008) and healthcare services (Katuu 2015; Marutha 2011). Records are especially important in hospitals as they are needed for confirming background information (Marutha 2011:2).

Despite the importance of medical records, these are often not managed correctly, which results in medical practitioners being unable to access information about previous diagnoses, treatments and prescriptions. If medical records are not managed properly, they can be lost forever. Missing or incomplete files can have a negative impact on the lives of patients. Newspapers reported that Polokwane Hospital in Limpopo was unable 'to provide medical records for one of the chronic patients suffering from cervical cancer' (Maponya 2013:6). According to Marutha (2017:1):

the file was to be used for further treatment by the patient's private doctor to conduct radiotherapy for the patient, but before that he needed medical records to get information about the patient's medical history.

Note: This article is partially based on the author's thesis of the degree of Master of Information Science at the University of South Africa, South Africa, with promoter Prof. P. Ngulube, received December 2011, available here: http://uir.unisa.ac.za/bitstream/ handle/10500/5737/thesis_marutha_n.pdf?sequence=1 
However, medical records and X-rays of the patient could not be found. This resulted in the doctor being unable to proceed for fear of giving the patient wrong treatment. The life of the patient was at stake as a result of unavailability of records.

In another case, Marutha (2011:3) reports that at Nkhensani Hospital in Giyani town, Limpopo, doctors 'could not operate on a patient because of a missing file'. In this case, the patient was involved in a motor vehicle accident in 2005 which left her leg partially paralysed. The doctor needed the file that contained information about her accident and health problems to trace the history or the seriousness of the injuries before risking an operation. Unfortunately, the only available record was about the patient's diabetes. As a result, the Limpopo Department of Health and Social Development intervened and clarified that the hospital had a problem with the files. The reason given was that the hospital relocated in 2007 and the files were not lost, but were 'somewhere in the hospital'.

The ineffective management of records is not only a South African problem. In the United States, the Department of Health and Human Services (2006) reports that the ratio of missing files in healthcare institutions is one out of seven. This is attributed to poor records management. Therefore, it is important that medical records should be managed properly so that citizens can receive proper and accurate health care. The consequences of improper records management are that citizens can lose their lives or become permanently paralysed because of a wrong diagnosis based on a lack of medical history. This can result in the government being litigated and paying millions because of missing files. This study sought to investigate the role of medical records in the provision of healthcare in Limpopo.

\section{Contextual setting}

The Department of Health in the Limpopo province was established with the purpose to render healthcare services within the province. Limpopo is located in the far north of South Africa and it is divided into five districts, namely: Capricorn, Mopani, Sekhukhune, Vhembe and Waterberg. Each of these districts is further divided into five sub-districts or local municipalities. The Department, through its various hospital facilities, creates medical records when rendering healthcare service delivery (Marutha 2011:2). These records are used for various purposes, for example, 'for nursing and clinical audits in the peer review meetings which are conducted regularly in hospitals' (Marutha 2011:2). These records are used to:

screen the business transactions conducted by doctors and nurses. They confirm the procedures followed when doctors and nurses conducted certain critical patients' treatment activities such as child delivery and operations, as well as investigating maternal death. The hospitals also regularly use medical records in response to legal actions/litigations or complaints from the patients or citizens about hospital services rendered. (Marutha 2011:3)

In addition, 'the patients' records are also used daily to further record information about the patients' personal details, prescriptions and diagnosis for future reference and for follow-up patients. The information recorded is eventually used to confirm the patients' health history during current and future consultations' (Marutha 2011:3). Marutha (2011:3) emphasises that 'the pace at which the records are retrieved and served for this purpose determine the patient waiting time for the services. This has an impact on the quality of the service rendered by the health institution'. By 2004, the average waiting period for a patient in Limpopo hospitals had been 5 hours and 5 minutes (Limpopo Department of Health and Social Development 2006:85). Even though the Limpopo Department of Health had planned to reduce the time to less than 3 hours, Marutha (2017:136) reports that it remained unchanged in 2017.

\section{According to Marutha (2011:4):}

records in hospitals are used to collect and validate statistical information daily. The statistics collected are used to regularly review the hospital's monthly performance in all activities. It is through proper records management that the data collected can be complete and accurate.

Barry (2001) suggests that in order for records management to contribute meaningfully to health care provision, health care institutions need to implement a digital records system. According to Barry (2001), 'digital records system is a legitimate option which is cheaper in terms of money, time and energy to ensure speedy retrieval of records'.

The Department of Health in Limpopo uses a hybrid system for creating and managing records. However, even though the Department maintains medical records in digital and analogue format, the digital format is not complete as it excludes prescriptions, diagnoses and treatments. The digital format only covers personal details of the patient, dates of consultation and financial status regarding payments of consultation (Marutha 2011:4).

\section{Research problem}

In South Africa, it is often reported in the media that healthcare practitioners are unable to provide timeous and efficient healthcare services partly because of poor records management (Katuu 2015). This results in patients waiting long before they could be helped as the records cannot be retrieved or medical files are lost. In such instances, health workers are unable to assist patients. According to Marutha (2011:5):

this is due to the fact that, if the health worker proceeds treating patients without enough information about patients' healthcare background, they may end up rendering poor health services that may be risky to the patients' health.

This can have serious repercussions for the health providers and hospital's service delivery reputation. It would seem that records are not managed properly because of a lack of skills from the staff, infrastructure, budget constraints and a lack of support from oversight mechanisms such as public archives repositories (Nengomasha 2013:66; Ngoepe 2016). Therefore, 
there is a need for proper records management practices to ensure efficient retrieval of records that supports the provision of medical healthcare service in hospitals (Robek, Brown \& Stephens 1995). Otherwise, public hospitals will continue to be inefficient in providing services to patients and thus damaging their reputation.

\section{Research purpose and objectives of the study}

The purpose of this study was to investigate the role of records management in the provision of healthcare service delivery in Limpopo. The specific objectives were to:

- examine how records are managed to support healthcare services

- identify the root causes of missing medical records that hinder the provision of healthcare services in the Limpopo province

- make recommendations on the management of medical records.

\section{Literature review}

Besides their administrative value, records are managed in hospitals to support healthcare providers with patients' medical history. According to Marutha (2011:4), 'medical records assist the organisation with information about the treatment history and individual care experience that is regularly updated as the patient consults further. They are used for decision-making in the future course of treatment'. Therefore, these records need to be protected against destruction to ensure that they can be retrieved when needed. Several types of records created in hospitals include 'bed statistics, daily returns, day and night handover, nursing records and medical records' (Booyens 2001:153; Davidson 2000:199-200; Rampfumedzi 2006:18-19), 'patient information leaflets, handover books and records, maternity records and out of hours records' (Cowan \& Haslam 2006:266-267). According to Marutha (2011:5):

the bed statistics are created and preserved to provide information about bed occupancy in different wards, patients' conditions and discharges so that administrative staff knows which beds are available for new admissions while the daily returns are created and preserved to keep a written report about patients' admissions, discharges, deaths and transfers.

This assists with shift changes amongst 'day/evening shifting staff, administrative staff and management regarding the condition of patients in different wards' (Booyens 2001:153; Davidson 2000:199-200; Rampfumedzi 2006:18-19). In addition:

\footnotetext{
day and night handover records are created during the formal shifting handover reporting to the nurse to check in for work. This is for them to know and understand the condition of each patient they will be nursing and the information about what happened before they took over. The nursing records are 'written nursing communication', and that makes all nurses aware of each patient's background.
}

According to Rampfumedzi (2006:19), 'this type of records also assists in planning for patients' needs'. It is important that records are created as Booyens (2001:153) argues that the 'creation of records also document the doctor's delegations, admissions, treatment of patients, investigations to be conducted by the doctor and the care necessary at home, if there is any need'. Therefore, it is important that records are created and managed properly in the healthcare institutions in order to support provision of health care.

Cowan and Haslam (2006:266) identify other types of records as the parent-held records which contain baby developmental information, immunisation details and milestones achieved, the refrigeration and freezer records/ charts contain laboratory and equipment records'. To Davidson (2000:197-200):

medical records are categorised into genre, such as nurses' notes, patient demographic data, physicians orders, progress reports, laboratory test results, pathology reports, radiology reports and images. The records are created based on observation, interpretation of data, treatment plans and patients outcomes. These records provide evidence of patient consultation, outcomes and health service rendered at the hospital.

It is important that these records are managed properly in future when diagnosing patients to prevent incorrect diagnoses resulting in death and litigations.

\section{Research methodology}

This study utilised quantitative data collected through questionnaires directed to staff members in the information management and records management unit at the hospitals in Limpopo. This study consisted of 40 hospitals in the province and the respondents were drawn from the records management and the information management units, which had a staff complement of 324 employees. These units were relevant for the study as they use medical records of patients daily to discharge their duties. The hospitals were first stratified and a proportion sampling of respondents was drawn from each hospital. As a result of using Rasoft sample calculator, out of 324 of the total population of the study, $65 \%$ (210) were sampled as guided by the scientific calculator for sampling. The study utilised the confidential level of $90 \%$ and $5 \%$ margin of error. From the sample of 210, the records management staff constituted $74 \%$ (155) while the information management proportion was $26 \%$ (55). Out of 210 questionnaires distributed, only 162 were returned, representing a response rate of $77 \%$. The study utilised MS Excel ${ }^{\circledR}$ spreadsheet database to analyse the quantitative data. The tally-sheet was used to capture data from respondents as they responded and the spread sheet was used to capture the sum of data from the tally-sheet for each question and answer, calculate percentages, and sketch graphs based on the data captured.

\section{Research findings}

This section presents the results based on the objective of the paper. 


\section{Management and administration of medical records to support healthcare services}

When asked to rate the state of records management, $15 \%$ (24) of respondents indicated that the state of records management in their institutions was very poor, 58\% (94) stated that it was poor while 1\% (2) were unsure about the state of records. Additionally, 22\% (36) indicated that it was in a good state, while $4 \%$ (6) were of the view that the state of records in their institutions was very good. Figure 1 illustrates the results. Those who have indicated unsure, poor and very poor justified that at times records are requested in bulk, which makes the retrieval process lengthy. It was stated that there was too much paperwork, no proper filing/archiving system, poor planning, poor organisation and supervision, files are inexplicably lost as well as a lack of filing space. Furthermore, records management is a new concept in the hospitals; as a result, there is a lack of experienced officials and it is seen as an unimportant division, which leads to minimal budget allocation. The possible causes of the poor state of records management in hospitals which contributed to missing records were identified by respondents as:

- lack of good organisation and disciplinary measures for involved staff

- no proper filing system in place

- no designated staff

- lack of capacity, skills and training

- lack of administrative leadership and individual, official dedication

- usage of manual records management

- lack of filing space, which leads to a mixture of files in their different status like death and motor vehicle accidents

- staff are unfamiliar with records management, especially those who are also new to the field

- poor infrastructure

- little centralised budget

- poor planning

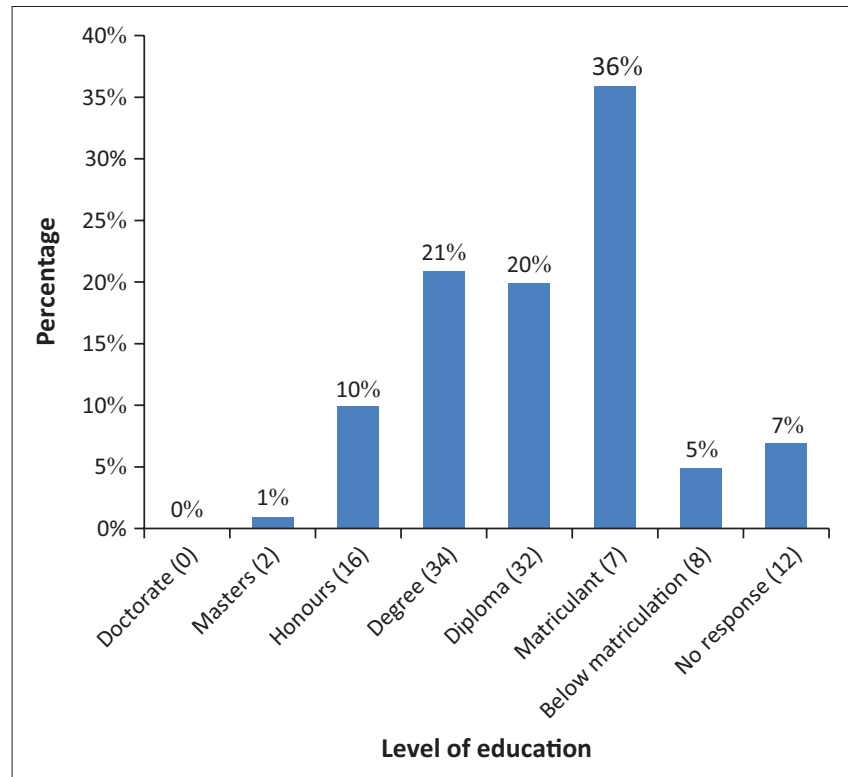

FIGURE 1: Respondents' educational levels $(N=162)$.
- lack of end users consultation when planning system and administration

- shortage of staff.

\section{The root causes of missing files that hamper the provision of healthcare services}

Proper implementation of records management policies, procedures and control measures

As indicated by $99 \%$ (161) of the respondents, some files were returned to the registry after more than a month. Files can be lost in the hands of users rather than those who are untrained in managing records. Proper records management ensures efficient retrieval of records to support healthcare service. Records that are managed properly can easily be tracked and thus minimise missing files. It was established that the hospitals did not have a standard, reasonable time frame for the returning of patient records when users borrow files. This was compounded by the fact that the records management policy and procedures were silent on the issue of returning files.

\section{Medical records management resources}

The study reported that $46 \%$ (75) of the respondents stated that the availability of resources for records administration was less than $25 \%$, 35\% (56) stated it was between $26 \%$ and $50 \%, 9 \%$ (14) stated it was between $51 \%$ and $75 \%, 7 \%$ (11) stated it was between $76 \%$ and $100 \%$ and $4 \%$ (6) of the respondents did not answer.

\section{Records management education, training and knowledge}

When asked about training received, $94 \%$ (153) of respondents indicated that they never received any training in policies, procedures, norms and standards for managing records, while only $6 \%(8)$ stated that they received such training. Respondents believed that the problems in records management emanated from lack of awareness and training; lack of system monitoring and auditing; unqualified records management staff; lack of space for filing and optimal filing system; no consultation with end users or records management staff by IT when planning system and administration.

In most instances, officials who are not trained in records management become demoralised and uninterested in the work and merely do it for the sake of receiving a salary. The educational level of respondents entails that none of the respondents had a doctorate, $1 \%$ (2) had a Master's degree, $10 \%$ (16) had an honours degree, 21\% (34) had a degree, $20 \%$ (32) had a diploma, 36\% (58) matriculated and 5\% (8) had a qualification lower than matric while $7 \%$ (12) of the respondents did not respond. Figure 1 illustrates the results. The respondents stated percentages of officials trained in records management. Out of all respondents, $6 \%$ (10) stated that none of the officials were trained, $59 \%$ (96) stated that less than $25 \%$ were trained, $14 \%$ (23) stated that $50 \%$ were trained, $5 \%$ (8) stated that $75 \%$ of staff were trained, only $2 \%$ (3) stated that $100 \%$ records management staff were trained and 14\% (22) did not answer. Respondents 
were also requested to state the kind of training that was offered in their institutions. Out of all respondents, 81\% (132) stated that the training was offered in-house by internal staff, 36\% (58) stated in-house by a private trainer, $51 \%$ (82) stated that the training was conducted by an external institution and $8 \%$ (13) did not respond. Furthermore, 58\% (94) stated that in-house training was conducted by the manager, $53 \%$ (86) stated that it was by the supervisor, $44 \%$ (72) stated that it was by the provincial office and 19\% (31) did not answer.

From the findings, it appears that only a few officials working for records management in the public hospitals completed qualifications in records management. That is one of the contributing factors to not being able to manage records properly. Considering the educational field of study, 6\% (9) respondents studied records management, 39\% (63) studied information management, 4\% (7) knowledge management, $1 \% \quad$ (2) studied history, $82 \% \quad(134)$ studied public administration, $8 \%$ (13) studied nursing and 25\% (41) studied other courses not listed, such as human resources, information and communication technologies (ICT) and financial management. Furthermore, 4\% (6) respondents did not give an answer. Figure 2 indicates respondents' post-matriculation educational field of study. The study revealed that the majority $82 \%$ (134) of respondents had public administration qualifications, 39\% (63) had information management qualifications and 25\% (41) had other courses not listed, such as human resources.

When asked about experience, 82\% (133) of the respondents had more than 5 years' experience in their current position while $86 \%$ (139) had more than 5 years of records management experience as illustrated by Figures 3 and 4, respectively.

The survey also discovered that $100 \%$ (162) of the respondents were confident about their knowledge of the meaning of records. Eighty-nine per cent (144) stated that records are recorded information and/or information created during communication or business transaction. The examples of records mentioned were $79 \%$ (128) memos and registers and $100 \%$ (162) said patient files.

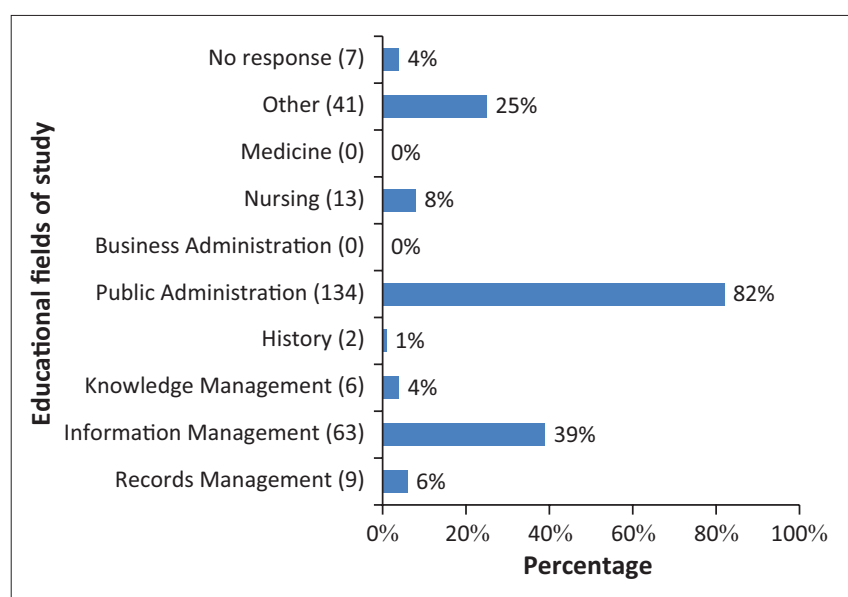

FIGURE 2: Respondents' post-matriculation educational fields of study $(N=162)$.
The survey indicated that 70\% (114) of the respondents had never attended formal records management training and 88\% (142) claimed that no formal records management training was offered to records management staff in their institutions. If the training was offered as stated by $63 \%$ (103), the competency level of the training was basic. When asked about training of officials on records management, only $6 \%$ (10) of the respondents stated that they were not trained in records management, while $94 \%$ (152) had received the training. Respondents indicated that training on records management was offered in-house by internal staff, by a private trainer such as consultants from Metrofile and the Document Warehouse (records management consultant companies) and institutions of higher learning, especially the University of South Africa. According to the respondents, the training offered covered records management areas such as classification systems, records creation, retention, appraisal and disposal as well as archival legislation. The respondents felt that the training was theoretical in nature with little practical training. As such, it was difficult to implement what they have learnt from the training. They felt that future training should cover digital records as it is a modern system of management.

\section{Discussions of the findings}

Ojo (2009:95) contends that 'development in Africa is still blocked by lack of ICT, illiteracy, politics, poor infrastructure

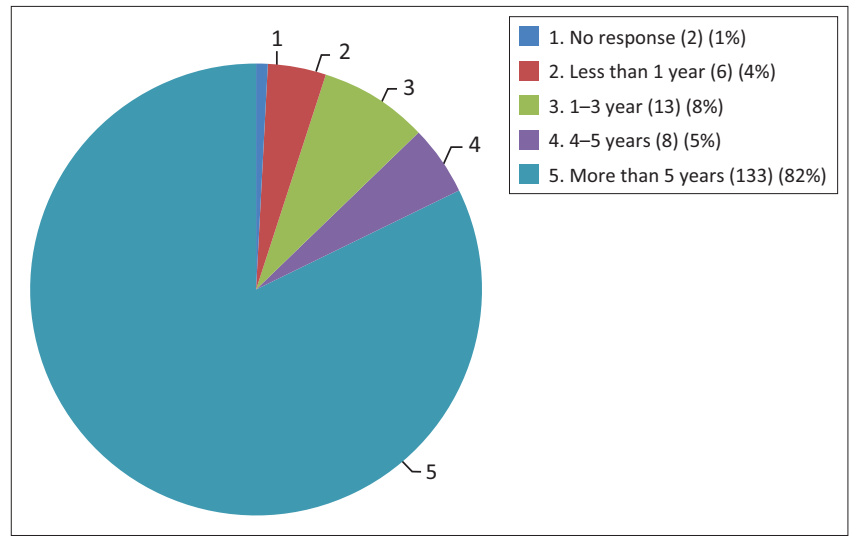

FIGURE 3: Respondents' length of service in the current position $(N=162)$.

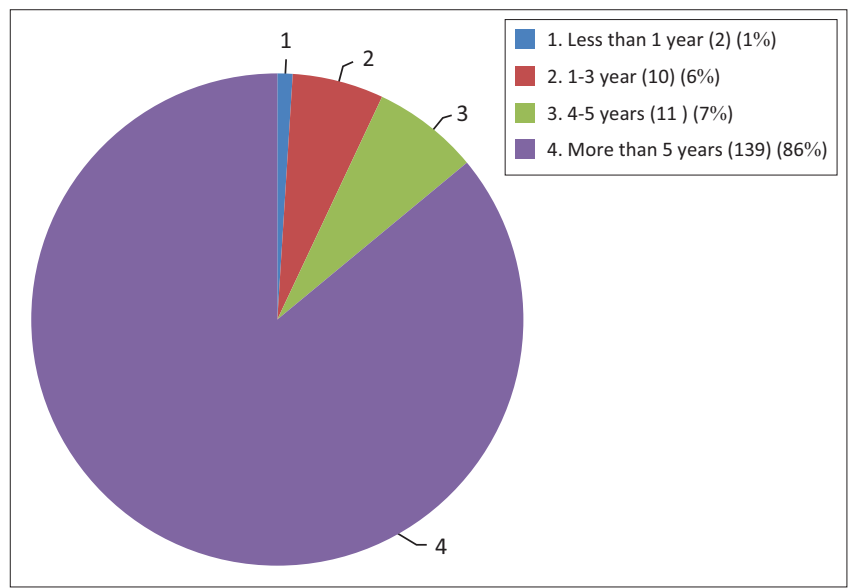

FIGURE 4: Respondents' length of experience in the current field of work specialisation $(N=162)$. 
and human resources'. This is the case in almost all countries in sub-Saharan Africa as they experience lack of support for resources, expertise and electronic media management facilities, which lead to poor management of digital records (Ngulube \& Tafor 2006:69). This further had bad consequences for all citizens' information needs. For instance, missing files in the healthcare institutions may be emanated from several factors, including but not limited to: lack of or poor quality in the available policies; procedures and control measures that cover inappropriate scope and principles; lack of management support and inadequate resources and staff. Another major contributing factor to the missing files is the lack of appropriate education, training and knowledge for management of records, particularly medical records. The missing files have a negative impact on the provision of healthcare services. Marutha (2011:181) identifies issues contributing to missing files in the hospitals as 'vacancy rate, staff turnover, resources availability, management support, records management programmes functionality, staff competency and skills'. The missing files also contribute towards exceeding file retrieval turnaround time norm and/ or target. Records that are not properly managed lead to time-consuming factors such as misfiling, untidy filing and challenges arising from a high records demand. If records are not managed properly in hospitals, this could result in a loss of human lives, as medical practitioners would not have any record to refer to. The problem of missing files was compounded by the fact that the hospitals were using manual systems as file tracking.

Many factors may contribute towards missing files in the healthcare institutions. Katuu and Ngoepe (2015:192) identify the education and training programme as a key challenge of addressing records management capacity deficit in South Africa. This is not only unique to South Africa as there are few archives and records management educational programmes throughout the African continent. As a result, very few practising archivists and records managers in Africa have the relevant qualification as evident by the Department of Health in Limpopo. Many public organisations in South Africa experienced challenges in managing records because of limited skills, infrastructure and lack of policies and controls (Nengomasha 2013:2). These challenges were also identified in this study. In most instances, 'poor recordkeeping results in missing and lost files and documents, which leads to delayed service to citizens and poor image of the public service' (Marutha 2011:180). This poor state of records management also contributed to missing files in hospitals. Similarly, Limpopo healthcare service delivery hospitals experienced inadequate training, unrelated skills and competencies and inadequate record-keeping system. Looking at the education, training, skills and knowledge in the hospitals, most of the officials had more than 5 years of experience in their current position and more than 5 years of records management experience. The officials were confident about their knowledge of the meaning of records, which they indicated is recorded information and/or information created during communication or business transactions. The examples of records mentioned were memos, registers and patient files. The majority of officials in the hospitals did not attend formal records management training, as such training was not offered to the staff. The in-house training was conducted by the internal staff, although irregularly. The only training that was attended by less than $25 \%$ officials was at the basic competency level.

According to Chinyemba and Ngulube (2005), qualified records management staff in an organisation ensures that records management work is carried out efficiently. Employees need to be capacitated with the knowledge and skills to develop and maintain the records management programme. The knowledge required should cover all the processes of records management. According to Katuu (2015), this should be supplemented by contextual knowledge including 'administrative history, professional elements of law, social, cultural, legal and financial systems, information system and management of digital records'. Lack of training on records management may culminate into files missing as the officials might not have the skills to manage the records properly. In an organisation where the staff competency and skills are not developed, the survival of the organisation is not assured. Qualified and well-trained staff will lead the organisation to an advanced stage of operation, growth and quality of work (King 1997:658).

The hospitals were also disturbed by too much paperwork; no proper filing/archiving system; poor planning, organisation and supervision; many files lost with no known reason; lack of filing space; lack of experienced officials; records management division undermined; and little centralised budget. The poor state of records management in hospitals that resulted in records going missing and being misfiled also entails lack of good organisation and disciplinary measures for involved staff; no proper filing system in place; no properly designated staff; lack of capacity, skills and training; lack of administrative leadership and individual official dedication; use of manual records management; lack of filing space; a lot of staff not familiar with records management; poor infrastructure; poor planning; lack of end-user consultation when planning the system and administration; and shortage of staff (Marutha 2011:204).

The manual record-keeping, especially for a large volume of patient records, also led to most records going missing. The missing files were caused by, amongst others, misfiling, untidy filing, staff shortage and high records demand. Other reasons were incompetent/unskilled staff, damage to record and lack of general staff awareness about the importance of records and insufficient budget. It was also affected by lack of support for resources to support records management programmes. Poor records tracking system also led to records missing. The hospitals were using the manual file tracking system. They did not have a standard reasonable time frame for returning of patient records when clients borrowed files (Marutha 2011:204).

This was also discovered by Ngoepe and Van der Walt (2010:96) in their study about a framework for a records 
management programme in the Department of Cooperative Governance and Traditional Affairs in South Africa. 'This is the reason some files were returned after more than a month. The hospitals did not have policies, procedures, norms and standard documents that specifically govern patient records management' (Marutha 2011:205).

\section{Conclusion and recommendations}

It is clear from the discussion that missing files contributed to patients waiting long to be assisted. As a result, nurses and doctors are unable to assist patients or treat the patients immediately. In order to provide corrective measures to misfiling, it is necessary that experienced people are employed. These staff members should be trained regularly through short learning programmes offered at institutions of higher learning to keep their skills up to date. As Thurston (2005) would concur:

Effective records management is important to avoid files piling up in different offices and corridors. Effective records management should be supported by avoiding sending difficult or poor performing personnel to the records management unit, by ensuring continuous training, creating policies, procedures and standards, and also ensuring that all officials consider records significant, as well as ensuring that proper disposal measures are put in place.

Furthermore, 'there should also be a political will and management support in hospitals to support the implementation of effective records management' (Marutha 2011:212).

The hospitals should adopt and implement an effective records system to avoid or minimise too much paper work. They should also fill their vacant posts as necessary and come up with a staff retention strategy to prevent high staff turnover. Hospitals should develop and implement a standard reasonable time frame for returning patients records when clients borrow files to measure their performance in terms of healthcare support and to prevent files from going missing (Marutha 2011:212).

They should also develop policies, procedures, norms and standard documents that specifically govern patient records management. Security measures in hospitals should also be maximally strengthened to avoid file theft, unauthorised destruction and alteration. As much as they had the basic security measures, they should consider moving to a higher level of security technology such as card or fingerprint access control, as well as surveillance cameras at strategic points of records custodies and registries. They should also bring about temperature and humidity control measures such as air conditioners in records custody places; air conditioners should be set at $18-20^{\circ} \mathrm{C}$ as guided by the National Archives and Records Service of South Africa (NARSSA) (Marutha 2011:212).

The Department should consider implementing an electronic records management system that is capable of capturing and providing access to a full patient record, as well as tracking paper records movement irrespective of the location. As records practitioners require skills in electronic records management, the Department should invest in capacity building, including training and provision of sustainable infrastructure required to manage digital records. As Ngoepe (2017:41) would attest, the skills acquired will enable records practitioners to fully participate in the planning of digital records systems and thus be able to support effective healthcare services.

\section{Acknowledgements Competing interests}

The authors declare that they have no financial or personal relationship(s) which may have inappropriately influenced them in writing this article.

\section{Authors' contributions}

N.S.M. conceptualised the paper, collected data and wrote the article and contributed $60 \%$ to the article. M.N. assisted in conceptualisation, supervised the study and edited the article, contributing $40 \%$ to the article.

\section{References}

Barry, R.E., 2001, 'Electronic document and records management systems, towards a methodology for requirements definition', viewed 3 April 2016, from http://www. caldeson.com/RIMOS/barry1.html\#six

Booyens, S.W., 2001, Introduction to health services management, 2nd edn., Kenwyn, Juta.

Chinyemba, A. \& Ngulube, P., 2005, 'Managing records at higher education institution: A case study of the University of KwaZulu-Natal, Pietermaritzburg Campus', South African Journal of Information Management 7(1), viewed 24 July 2016, from http://www.sajim.co.za/index.php/SAJIM/article/download/250/241

Cowan, J. \& Haslam, J., 2006, 'Clinical risk management managing NHS records: Complying with the new code of practice: Clinical governance', An International Journal 11(3), 262-269.

Davidson, E.J., 2000, 'Analyzing genre of organizational communication in clinical information system', Information Technology and People 13(3), 196-209. https:// doi.org/10.1108/09593840010377635

Katuu, S., 2015, 'Managing records in South African public health care institutions: A critical analysis', PhD Thesis, University of South Africa.

Katuu, S., 2016, 'Transforming South Africa's health sector-the eHealth strategy and the implementation of electronic document and records management (EDRMS) and the utility of maturity models', Journal of Science and (EDRMS) and the utility of maturity models', Journal of Science and
Technology Policy Management 7(3), 330-345. https://doi.org/10.1108/ Technology Policy Man
JSTPM-02-2016-0001

Katuu, S. \& Ngoepe, M., 2015, 'Managing digital heritage: An analysis of the education and training curriculum for Africa's archives and records professionals', Digital Heritage 2, 191-194. https://doi.org/10.1109/Digital Heritage.2015.7419488

King, L.A., 1997, 'Are you managing your vinyl effectively?', Management Decision 35(9), 656-659. https://doi.org/10.1108/00251749710186487

Limpopo Department of Health and Social Development, 2006, Annual Report 2006/07 Health (Vote 7), viewed 20 November 2016, from http://www.dhsd. limpopo.gov.za/

Maponya, F., 2013, 'No medical records, no treatment', Sowetan newspaper, 10 April, p. 6.

Marutha, N.S., 2012, 'Electronic records management in the public health sector of the Limpopo province in South Africa', Journal of the South African Society of Archivists 45, 39-67.

Marutha, N.S., 2011, 'Records management in support of service delivery in the public health sector of the Limpopo province in South Africa', MINF Thesis, University of South Africa.

Marutha, N.S., 2017, 'A framework to embed medical records management into the healthcare service delivery in Limpopo Province of South Africa', PhD Thesis, University of South Africa.

Nengomasha, C.T., 2013, 'The past, present and future of records and archives management in sub-Saharan Africa', Journal of the South African Society of Archivists 46, 1-11.

Ngoepe, M., 2008, 'An exploration of records management trends in the South African public sector: A case study of the Department of Provincial and Local Government', MINF Thesis, University of South Africa. 
Ngoepe, M., 2012, 'Fostering a framework to embed the records management function into the auditing process in the South African public sector', PhD Thesis, University of South Africa.

Ngoepe, M., 2016, 'Records management models in the public sector in South Africa: Is there a flicker of light at the end of the dark tunnel?', Information Development 32(3), 338-353. https://doi.org/10.1177/0266666914550492

Ngoepe, M., 2017. 'Archival orthodocy of post-custodial realities for digital records in South Africa', Archives \& Manuscript 45(1), 31-44. https://doi.org/10.1080/0157 6895.2016.1277361

Ngoepe, M. \& Van der Walt, T.B., 2010, 'A framework for records management programme: Lessons from the Department of Cooperative Governance and Traditional Affairs', Mousaion 28(2), 83-107.

Ngoepe, M. \& Makhubela, S., 2015, 'Justice delayed is justice denied': Records management and the travesty of justice in South Africa', Records Management Journal 25(3), 288-305. https://doi.org/10.1108/RMJ-06-2015-0023

Ngoepe, M. \& Ngulube, P., 2016, 'A framework to embed records management into the auditing process in the public sector in South Africa', Information Development 32(4), 890-903. https://doi.org/10.1177/0266666915573037
Ngulube, P. \& Tafor, V.F., 2006, 'The management of public records and archives in the member countries of ESARBICA', Journal of the Society of Archives 27(1), 57-83. https://doi.org/10.1080/00039810600691288

Ojo, T., 2009, 'Communication networking: ICT and health information in Africa', Information Development 22(2), 94-101. https://doi.org/10.1177/0266666906065549

Rampfumedzi, D.P., 2006, 'Quality control of obstetric nursing records in a selected regional hospital', MA Health Studies Thesis, University of South Africa.

Robek, M.F., Brown, G.F. \& Stephens, D.O., 1995, 'Why records management? Ten business reasons', viewed 30 July 2016, from http://www.epa.gov/records/what/ quest1.htm

Thurston, A., 2005, 'Fostering trust and transparency through information system', PREM Notes Public Sector, no. 97, The World Bank, Washington, DC, viewed 30 July 2016, from http://documents.worldbank.org/curated/en/469671468329484494/ Fostering-trust-and-transparency-through-information-systems

U.S. Department of Health and Human Services, 2006, 'Consumer awareness, addressing healthcare connectivity as a matter of life and death', viewed 31 July 2016, from http://www.hhs.gov/healthinformationtechnology/consumer Awareness.htm 